УДК 620.193

ВЛИЯНИЕ НЕПРОГНОЗИРУЕМЫХ ФАКТОРОВ

НА КОРРОЗИОННЫЕ ПОВРЕЖДЕНИЯ

ТРУБОПРОВОДОВ И ОБОРУДОВАНИЯ

\title{
UNPREDICTABLE FACTORS INFLUENCE ON CORROSION DAMAGE TO PIPELINES AND EQUIPMENT
}

\author{
Р.Н. Узяков, Ю.А. Чирков, В.М. Кушнаренко, Е.В. Пояркова
}

Оренбургский государственный университет,

г. Оренбург, Российская Федерация

Rafael N. Uzyakov, Yuriy A. Chirkov,

Vladimir M. Kushnarenko, Ekaterina V. Poyarkova

\section{Orenburg State University, Orenburg, Russian Federation}

Аннотация. В статье представлен анализ коррозионных повреждений трубопроводов и оборудования. Показано, что в ряде случаев использование традиционных подходов к диагностике повреждений не позволяет дать однозначный ответ о причинах, обусловливающих возникновение подобных разрушений.

Выявлена причинно-следственная связь повышения скорости коррозии материалов наружной поверхности трубопроводов и оборудования, работающего с сероводородсодержащими средами, из-за выходящих на наружную поверхность ионов водорода, способствующих изменению водородного показателя раствора в кислую сторону. При этом коррозионные процессы на стальной поверхности резко интенсифицируются.

Значительное количество разветвляющихся трещин, образующих местами сетку на внутренней поверхности сферических 
распределительных камер теплообменников и шлемовых труб, вызвано резким охлаждением поверхности металла интенсивным дождем, при котором внутренняя поверхность подвергается несимметричным циклам по принципу «растяжения и сжатия». Показано, что растрескивание штуцеров теплообменников «амин - амин» происходит в результате воздействия дополнительных растягивающих сил и изгибающих моментов на штуцера. Дополнительные нагрузки возникли из-за изменения монтажного зазора между опорами корпусов теплообменников, что было вызвано атмосферной коррозией регулировочных листов.

Abstract. The article presents an analysis of corrosion damage to pipelines and equipment. It is shown that in some cases the use of traditional approaches to the diagnosis of damage does not allow to give definitive answer about the causes of the occurrence of such damage.

A cause-effect relation of increase corrosion rate of materials on the pipelines and equipment outer surface working with hydrogen sulfide-containing media due to hydrogen ions cropping out on the outer surface, contributing to a change in the solution $\mathrm{pH}$ in the acidic direction has been found. At the same time, corrosion processes on the steel surface are dramatically intensified.

A significant number of branching cracks forming in places a grid on the inner surface of the spherical distribution chambers of heat exchangers and overhead pipes is caused by a shock chilling of the metal surface by intense rain, in which the inner surface undergoes asymmetric cycles according to the principle of «tensile and compression». It is shown that cracking of the fittings of the "amine - amine» heat exchangers occurs as a result of the action of additional tensile forces and bending moments on the fitting. Additional loads arose due to changes in the mounting clearance between the supports of the heat exchanger bodies, which was caused by atmospheric corrosion of the adjustment sheets. 
Ключевые слова: коррозия; трещина; анализ; трубопровод; коррозионные повреждения; диффузионно-подвижный водород

Key words: corrosion; crack; analysis; pipeline; corrosion damage; diffusion-mobile hydrogen

Априори разрушения конструкций при их эксплуатации, приводящие к аварийным отказам, - относительно редкое явление. Для серийных изделий отказы составляют, как правило, не более тысячных долей процента от общего количества соответствующих, находящихся в эксплуатации изделий. Тем не менее, совершенно очевидна необходимость правильного установления причин разрушений деталей и конструкций для предотвращения их в дальнейшем. Особенно полезны результаты такого анализа в стадии доработки конструкции [1].

Анализ коррозионных разрушений конструкций включает в себя:

-анализ соответствующей технической документации;

-определение степени агрессивности среды;

-оценку эффективности противокоррозионных мероприятий;

-оценку уровня рабочих и эксплуатационных напряжений;

-оценку технического состояния поврежденного объекта;

-определение характера разрушения;

-традиционное исследование качества металла.

В большинстве случаев такого перечня диагностических мероприятий вполне достаточно для выявления причин разрушения и выработки рекомендаций для предотвращения возникновения аналогичных ситуаций.

Однако в некоторых ситуациях использование традиционных подходов к анализу разрушений не позволяет дать однозначный ответ о причинах, вызвавших их. В этих случаях необходим более широкий, комплексный и подчас неординарный подход к анализу разрушений. Предлагается к 
рассмотрению несколько случаев подобных коррозионных повреждений из собственной диагностической практики и экспертной деятельности.

Во-первых, наиболее частой причиной проявления на поверхности оборудования эксплуатационных повреждений является атмосферная коррозия наружной поверхности оборудования. Для месторождений сероводородсодержащего сырья специалисты-эксплуатационники производственных объектов практически все внимание уделяют внутренней коррозии по причине агрессивности сероводородсодержащей среды, которая вызывает общую и местную коррозию, а также коррозионное растрескивание. И в то же время вопросам атмосферной коррозии металла при действии сероводородсодержащих сред на внутреннюю поверхность трубопроводов и оборудования до сих пор не уделяется должного внимания. При коррозионном мониторинге оборудования и трубопроводов контролируется остаточная толщина стенки, при этом всю потерю металла обычно относят к внутренним процессам коррозии.

Величина потока диффузионно-подвижного водорода (ДПВ), проходящего через стенку изделий, контактирующих с наводороживающими средами, определяет степень активности коррозионных сред, в том числе учитывающую скорость электрохимических процессов, вероятность возникновения растрескивания, а также эффективность противокоррозионных мер [2].

Вместе с тем, водород в составе агрессивной среды способен оказывать существенное влияние на различные металлы. В процессе этого воздействия, как правило, наблюдаются потеря пластичности металла и возникновение разрушений при напряжениях ниже предела текучести материала оборудования вследствие поглощения водорода. В процессе эксплуатации атомарный водород, адсорбированный на поверхности оборудования, может проникать внутрь металла и приводить к его разрушению. В то же время при визуальном осмотре установлено, что 
наружная коррозия вносит определенный вклад в утонение стенок оборудования (рисунок 1). Снижение надежности такого оборудования и разгерметизация значительно увеличивают непроизводственные затраты по его эксплуатации, a также затраты, связанные с ликвидацией последствий аварийных ситуаций.

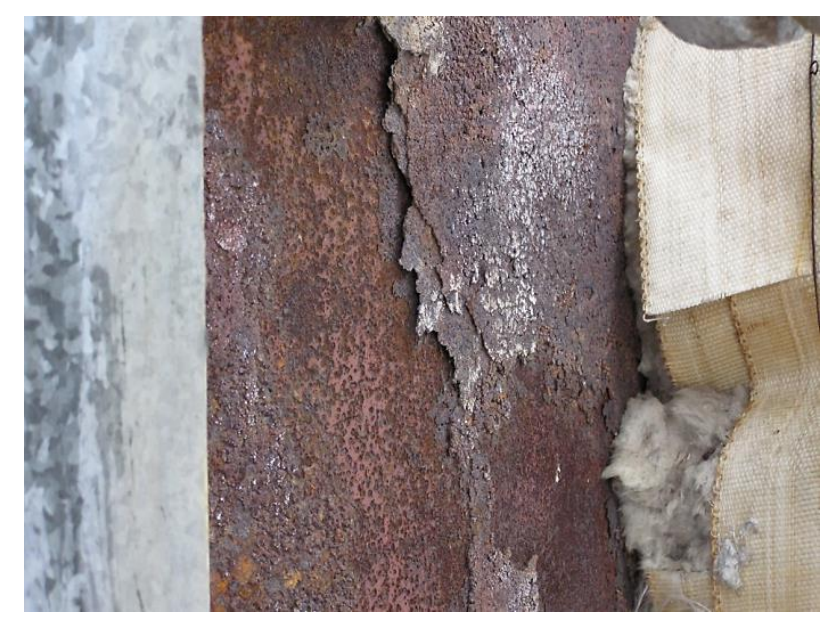

Рисунок 1. Состояние наружной поверхности сепаратора сырого газа

Трубопроводы сырого и товарного газа имеют различное состояние наружной поверхности (рисунок 2). Проведенные исследования показали, что величина потока диффузионно-подвижного водорода через стенки трубопроводов сырого газа лежит в пределах 2,5 мкА, что оценивается как нормальное. Повышенные скорости коррозии наружной поверхности трубопроводов и оборудования, работающего с сероводородсодержащими средами, обусловлены тем, что выходящие на наружную поверхность ионы водорода не молизуются до $\mathrm{H}_{2}$, а переходят в раствор в виде иона $\mathrm{H}^{+}$. При малом объеме раствора (тонкая поверхностная пленка) даже небольшое количество ионов водорода изменяет водородный показатель раствора в кислую сторону. При этом коррозионные процессы на стальной поверхности резко интенсифицируются [3, 4].

Во-вторых, интерес представляют случаи когда, казалось бы, не должно быть значительных коррозионных повреждений. В нескольких теплообменниках газ-газ, имеющих одинаковые конструкции, эксплуатирующихся более 30 лет, в зоне контакта с неагрессивным газом 
выявлены трещины. Вначале в шлемовой трубе, по которой в теплообменник поступает обессеренный газ, выявлена сквозная трещина. При детальном обследовании метала трубы в районе сварных швов выявлено большое количество разветвляющихся трещин (рисунок 3).

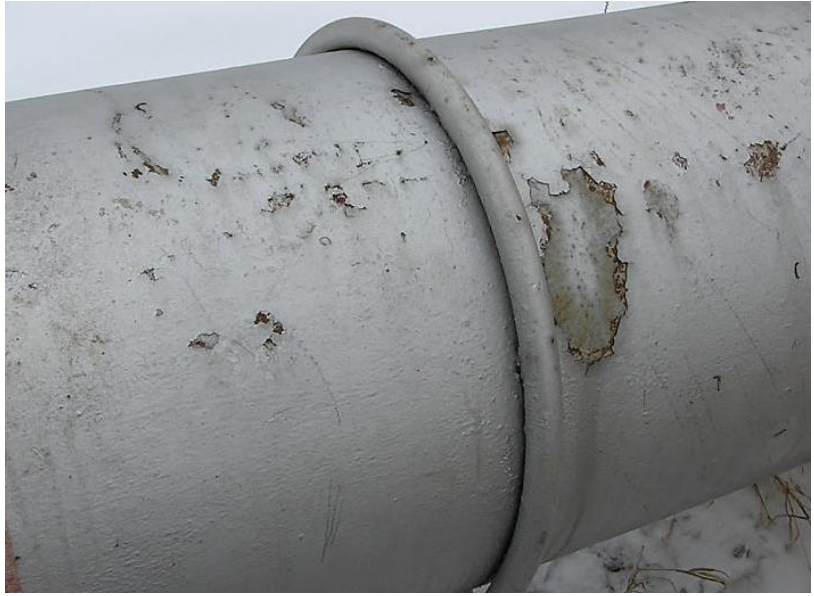

a)

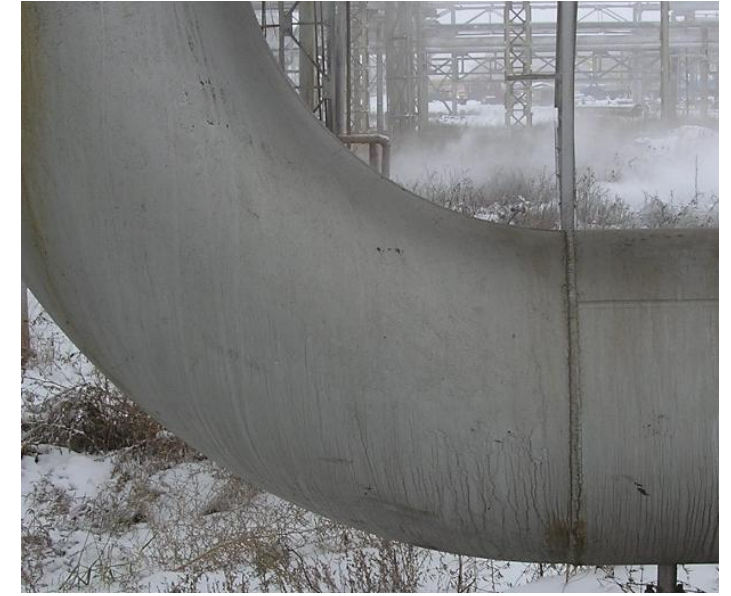

б)

Рисунок 2. Состояние наружной поверхности трубопровода сырого газа (а), товарного газа (б)

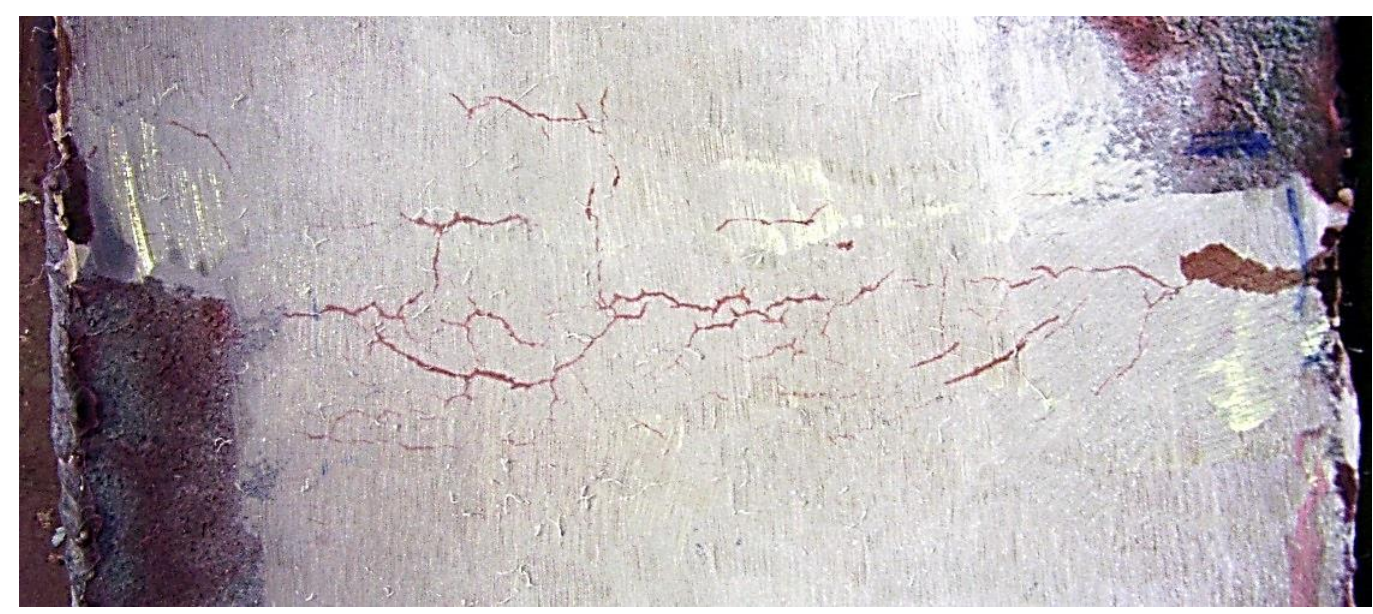

Рисунок 3. Трещины на внутренней поверхности шлемовой трубы (поверхность зачищена после цветной дефектоскопии)

В последующем на значительной части внутренней поверхности сферических распределительных камер теплообменников в зоне сварного шва выявлено значительное количество разветвляющихся трещин, образующих местами сетку (рисунок 4). 
На основании анализа иллюстративного материала, представленного на рисунках 3 и 4, установлено, что характер расположения трещин для распределительных камер теплообменников и шлемовой трубы имеет некоторые сходства, что связано с общей причиной образования трещин и различием в конструкции данных элементов.

Материальное исполнение повреждённых элементов:

- материал (пластичные стали): колпак - A42FP2; шлемовая труба A333Gr1;

- технологическая среда - обессеренный газ с содержанием сероводорода $-0,0004 \%$ об. и углекислого газа - 0,020 \% об.;

- температура обессеренного газа составляет $80{ }^{\circ} \mathrm{C}$;

- уровень рабочих напряжений - не превышал 0,43 от предела текучести материала.

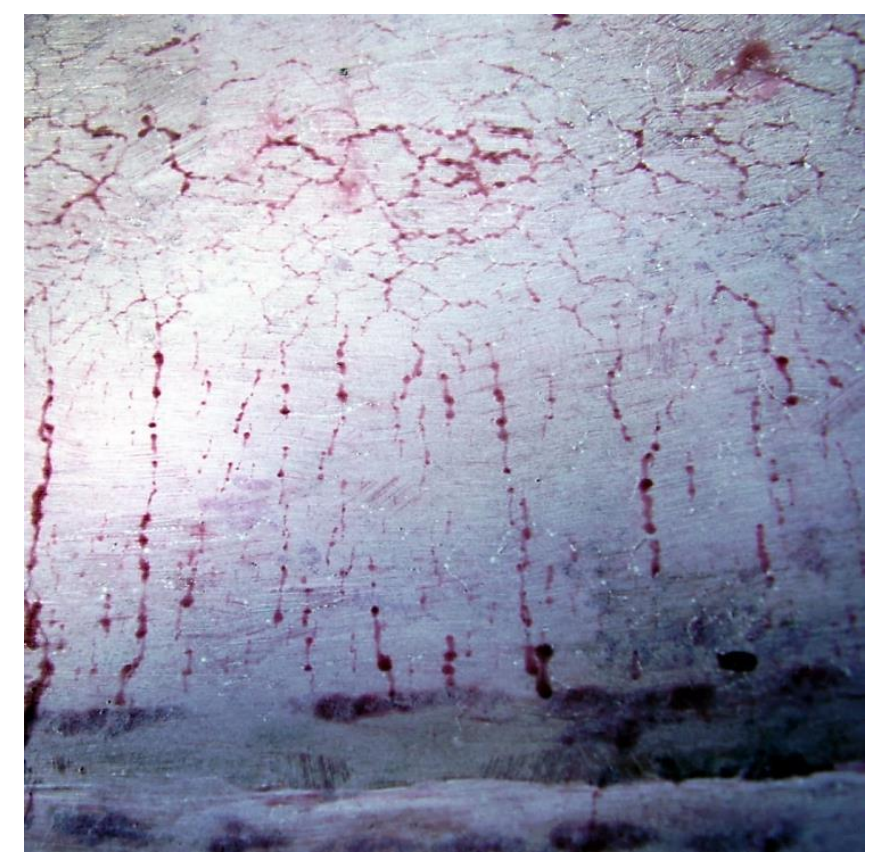

Рисунок 4. Трещины на внутренней поверхности распределительных камер теплообменников (цветная дефектоскопия)

Результаты исследований материала шлемовой трубы свидетельствуют о высоких механических свойствах после тридцатилетней эксплуатации, что позволяет сделать вывод о том, что и материальное исполнение было выбрано правильно и не является причиной разрушения. 
Анализ микроструктуры сварного соединения, а также тот факт, что трещины распространялись по основному металлу, зоне термического влияния и сварному шву, не локализуясь на каком-то конкретном участке, позволяют сделать вывод о том, что технология сварочно-монтажных работ была соблюдена и не явилась причиной повреждения конструкций.

Металлографические исследования показали, что механизм развития трещин межкристаллитный, a характер других выявленных трещиноподобных дефектов свидетельствует о наличии значительных напряжений, вызвавших данные повреждения. При наличии большого числа крупных трещин длиной более 100 мм и глубиной более трети толщины конструкция не разрушилась. Это указывает на тот факт, что значительное повышение напряжений было кратковременным и локальным в местах концентраторов напряжений.

Проведенный анализ показал, что причиной возникновения трещин могло быть только некое дополнительное циклическое воздействие, повышающее локальные напряжения до уровня предела текучести.

Как показано в работе [5], таким воздействием могло быть резкое охлаждение поверхности металла интенсивным дождем, при котором внутренняя поверхность подвергается внешнему влиянию нагрузок по принципу несимметричных циклов растяжения и сжатия. Концентраторами напряжений явились мелкие коррозионные язвы, где возникали пластические деформации, которые при небольшом числе циклов и дополнительном электрохимическом растворении вызывают образование коррозионных трещин. Трещины имели несквозной характер, так как с ростом их глубины снижался уровень термоциклических напряжений.

Выявлена еще одна причина проявления на поверхности оборудования эксплуатационных повреждений из-за непрогнозируемых факторов. В анамнезе за более чем тридцатилетний период эксплуатации 20-ти одинаковых теплообменников «амин - амин» и учёте совокупности 
сведений, полученных при диагностических процедурах, в обозначенном оборудовании были выявлены однотипные повреждения в металле 5-ти штуцеров (необычного типа трещины) и 6-ти штуцеров (утонение).

Вместе с тем, в исследуемых теплообменниках выявлена некоторая особенность. Несмотря на более агрессивную среду, с учетом хемосорбционной очистки по принципу насыщенного диэтаноламина (ДЭА), и значительно более высокое давление в трубном пучке, основная часть повреждений выявлена в штуцерах корпуса, работающего с менее агрессивной средой (регенерированный ДЭА). При этом проведенное ВНИИНефтемаш обследование оборудования установок сероочистки ряда газоперерабатывающих заводов показало, что в целом общая коррозия изготовленного из углеродистых и низколегированных сталей оборудования, как правило, незначительна [6].

Исследования металла не позволили однозначно выявить причину частых разрушений патрубков теплообменников. Сталь A333Gr1, из которой изготовлен штуцер, относится к сталям, стойким к воздействию сероводорода, пороговые напряжения для нее лежат в пределах 0,7-0,8 от предела текучести $\sigma_{\mathrm{T}}$. Вместе с тем, рабочие напряжения в металле патрубка равны 2,1 МПа, что составляет не более 0,01 от предела текучести $\sigma_{\mathrm{T}}$. Согласно данным стандарта NACE MR0175-97, сероводородсодержащими средами, вызывающими сульфидное растрескивание под напряжением, считаются среды, находящиеся под общим абсолютным давлением 0,448 МПа $\left(4,4\right.$ кгс/ $\left.\mathrm{cm}^{2}\right)$ и выше и при этом парциальное давление $\mathrm{H}_{2} \mathrm{~S}$ превышает 0,34 кПа. В теплообменниках рабочее давление в два раза ниже, а парциальное давление $\mathrm{H}_{2} \mathrm{~S}$ значительно меньше нижнего предела. Все это свидетельствует о том, что при проектном режиме эксплуатации коррозионное растрескивание в принципе не могло бы возникнуть. Коррозионное растрескивание возникает, если металл находится под действием значительных растягивающих напряжений, при 
этом трещины развиваются перпендикулярно направлению действия растягивающего напряжения.

Анализ повреждений показал, что повреждения располагались в секторе $120^{\circ}$ со стороны опор теплообменников, а трещины развивались в основном перпендикулярно продольной оси штуцеров. Это позволило сделать вывод о том, что на штуцеры действуют растягивающая сила и изгибающий момент, под влиянием которых они изгибаются выпуклостью в сторону опоры, чем и определяется ориентация повреждений.

В работе [7] также показано, что растягивающая сила и изгибающий момент, действующие на штуцеры, возникли в результате изменения монтажного зазора между опорами корпусов теплообменников. Это было вызвано атмосферной коррозией регулировочных листов (рисунок 5).

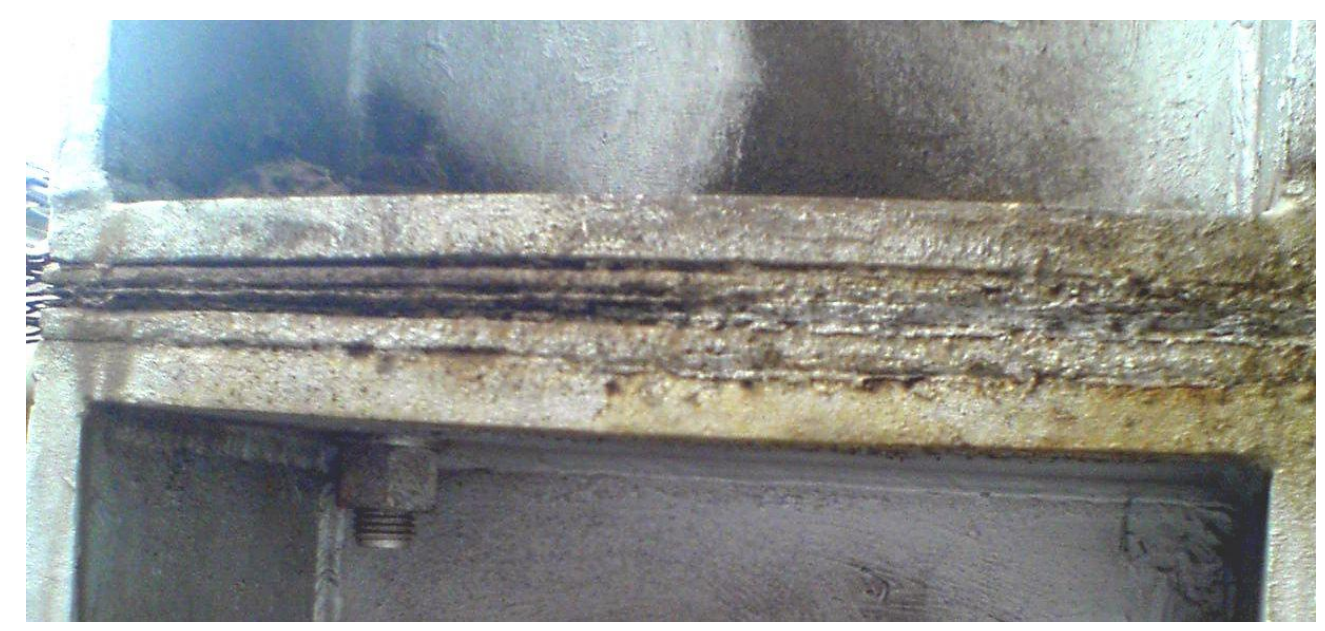

Рисунок 5. Атмосферная коррозия регулировочных листов теплообменников «амин - амин»

\section{Вывод}

При анализе коррозионного состояния оборудования необходимо уделять внимание как внешним непрогнозируемым факторам, способным вызвать значительные растягивающие напряжения, так и внутренним, воздействующим на наружные процессы, которые даже в условиях воздействия слабоагрессивных сред могут вызвать значительные повреждения технологического оборудования вследствие коррозии. 


\section{Список использованных источников}

1. Кушнаренко В.М., Репях В.С., Чирков Е.Ю., Кушнаренко Е.В. Дефекты и повреждения деталей и конструкций. Оренбург: ООО «Руссервис», 2012.531 с.

2. Гафаров Н.А., Гончаров А.А., Кушнаренко В.М. Коррозия и защита оборудования сероводородсодержащих нефтегазовых месторождений. М.: Недра, 1998. 437 с.

3. Настека В.В., Узяков Р.Н., Кушнаренко Е.В., Узяков М.Р. Особенности атмосферной коррозии трубопроводов и оборудования, работающего с сероводородсодержащими средами // Вестник ОГУ. 2005. № 9. C. 133-134.

4. Ингибиторы коррозии: в 2 т. Т. 2. Диагностика и защита от коррозии под напряжением нефтегазопромыслового оборудования / Н.А. Гафаров, В.М. Кушнаренко, Д.Е. Бугай и др.; под ред. Д.Е. Бугая и Д.Л. Рахманкулова. М.: Химия, 2002. 367 с.

5. Узяков Р.Н., Кушнаренко Е.В., Узяков М.Р. Коррозионное растрескивание сталей в слабоагрессивных средах // Прогрессивные технологии в транспортных системах: сб. докл. 7 Всеросс. науч.-практ. конф. Оренбург, ОГУ, 2005. С. 269-272.

6. Абдуллин И.Г. Коррозия. Современное состояние и развитие защиты от коррозии объектов нефтегазового комплекса. Уфа: УГНТУ, $2001.48 \mathrm{c}$.

7. Узяков Р.Н., Чирков Е.Ю., Кушнаренко В.М., Чуносов О.А, Ралко В.В. Коррозионное растрескивание стали в регенерированном растворе ДЭА // Диагностика оборудования и трубопроводов, подверженных воздействию сероводородсодержащих сред: матер. VII Междунар. науч.-техн. конф. Оренбург, 2008. C. 249-257. 


\section{References}

1. Kushnarenko V.M., Repyakh V.S., Chirkov E.Yu., Kushnarenko E.V. Defekty i povrezhdeniya detalei i konstruktsii [Defects and Damage to Parts and Structures]. Orenburg, OOO «Russervis», 2012. 531 p. [in Russian].

2. Gafarov N.A., Goncharov A.A., Kushnarenko V.M. Korroziya i zashchita oborudovaniya serovodorodsoderzhashchikh neftegazovykh mestorozhdenii [Corrosion and Protection of Equipment for Hydrogen Sulfide-Containing Oil and Gas Fields]. Moscow, Nedra Publ., 1998. 437 p. [in Russian].

3. Nasteka V.V., Uzyakov R.N., Kushnarenko E.V., Uzyakov M.R. Osobennosti atmosfernoi korrozii truboprovodov i oborudovaniya, rabotayushchego $\mathrm{s}$ serovodorodsoderzhashchimi sredami [Features of Atmospheric Corrosion of Pipelines and Equipment Working with Hydrogen Sulfide-Containing Media]. Vestnik OGU - Bulletin of OSU, 2005, No. 9, pp. 133-134. [in Russian].

4. Gafarov N.A., Kushnarenko V.M., Bugai D.E. e.a. Ingibitory korrozii:

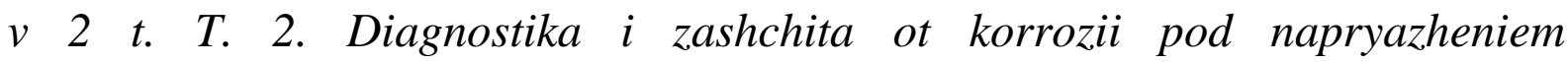
neftegazopromyslovogo oborudovaniya [Corrosion Inhibitors: in 2 vol. Vol. 2. Diagnostics and Protection against Corrosion under Stress of Oil and Gas Equipment]. Moscow, Khimiya Publ., 2002. 367 p. [in Russian].

5. Uzyakov R.N., Kushnarenko E.V., Uzyakov M.R. Korrozionnoe rastreskivanie stalei v slaboagressivnykh sredakh [Corrosion Cracking of Steels in Slightly Aggressive Environments]. Sbornik dokladov 7 Vserossiiskoi nauchno-prakticheskoi konferentsii «Progressivnye tekhnologii v transportnykh sistemakh» [Collection of Reports of 7th All-Russian Scientific and Practical Conference «Progressive Technologies in Transport Systems»]. Orenburg, OGU, 2005. pp. 269-272. [in Russian].

6. Abdullin I.G. Korroziya. Sovremennoe sostoyanie i razvitie zashchity ot korrozii ob"ektov neftegazovogo kompleksa [Corrosion. Current State and Development of Corrosion Protection of Oil and Gas Facilities]. Ufa, UGNTU, 2001. 48 p. [in Russian]. 
7. Uzyakov R.N., Chirkov E.Yu., Kushnarenko V.M., Chunosov O.A., Ralko V.V. Korrozionnoe rastreskivanie stali v regenerirovannom rastvore DEA [Corrosion Cracking of Steel in a Regenerated DEA Solution]. Materialy VII Mezhdunarodnoi nauchno-tekhnicheskoi konferentsii «Diagnostika oborudovaniya $i$ truboprovodov, podverzhennykh vozdeistviyu serovodorodsoderzhashchikh sred» [Materials of the VII International Scientific and Technical Conference «Diagnostics of Equipment and Pipelines Exposed to Hydrogen Sulfide-Containing Media»]. Orenburg, 2008, pp. 249-257. [in Russian].

\section{Сведения об авторах}

\section{About the authors}

Узяков Рафаэль Наильевич, канд. техн. наук, доцент, доцент кафедры механики материалов, конструкций и машин, ОГУ, г. Оренбург, Российская Федерация

Rafael N. Uzyakov, Candidate of Engineering Sciences, Associate professor, Assistant Professor of Mechanics of Materials, Constructions and Machines Department, OSU, Orenburg, Russian Federation

e-mail: uzraf@mail.ru

Чирков Юрий Александрович, д-р техн. наук, доцент, профессор кафедры механики материалов, конструкций и машин, ОГУ, г. Оренбург, Российская Федерация

Yurij A. Chirkov, Doctor of Engineering Sciences, Associate Professor, Professor of Mechanics of Materials, Constructions and Machines Department, OSU, Orenburg, Russian Federation

e-mail: chircov_ura@mail.ru 
Кушнаренко Владимир Михайлович, д-р техн. наук, профессор, заведующий лабораторией «Надежность», Автономная некоммерческая организация научно-технологический парк Оренбургского государственного университета «Технопарк ОГУ», г. Оренбург, Российская Федерация

Vladimir M. Kushnarenko, Doctor of Engineering Sciences, Professor, Head of the Reliability Laboratory, Autonomous non-profit-making organization Scientific and Technological Park of the Orenburg State University «Technopark OSU», Orenburg, Russian Federation

e-mail:vmkushnarenko@mail.ru

Пояркова Екатерина Васильевна, д-р техн. наук, доцент, заведующий кафедрой механики материалов, конструкций и машин, ОГУ, г. Оренбург, Российская Федерация

Ekaterina V. Poyarkova, Doctor of Engineering Sciences, associate professor, Head of Mechanics of Materials, Constructions and Machines Department, OSU, Orenburg, Russian Federation

e-mail: yarko.e@mail.ru 